\title{
PEMBELAJARAN ROBOTIK UNTUK MEMPERSIAPKAN GENERASI MUDA MENGHADAPI REVOLUSI INDUSTRI 4.0 DAN SOCIETY 5.0
}

\author{
F Faridawati $^{1}$, Eko Minarto ${ }^{1}$, Ika Istiana Wati ${ }^{1}$, Sutrisno $^{2}$, Lukman Hakim ${ }^{2}$ \\ ${ }^{1}$ Program Studi Fisika, Institut Teknologi Sepuluh Nopember (ITS), Surabaya, Jawa Timur, Indonesia \\ ${ }^{2}$ SDN Catak Gayam I , Jombang, Jawa Timur, Indonesia
}

\begin{tabular}{l}
\hline INFO ARTIKEL \\
\hline \\
Diterima: \\
Direvisi: \\
Disetujui: \\
\hline
\end{tabular}

Keywords:

Robotic;

Education;

Technology;

Industrial Revolution 4.0;

Society 5.0

\begin{abstract}
To prepare the young generation to face all the challenges that arise in the era of the industrial revolution 4.0 and society 5.0, it is necessary to work hard for educational institutions to educate their students to be ready to face the changing times. Improving the quality of education must start from the most basic level of education, namely the elementary school level (SD and $S M P)$. For this reason, a community service program was compiled, namely improving the quality of education by providing robotic learning training for elementary school (SD) students to become a generation ready to face all the challenges of the industrial revolution era 4.0 and society. 5.0. The results of the activity show that robotic learning suitable to be applied in schools as a school local content curriculum, and besides that robotic learning with the STEM action learning method is able to develop student competencies in the realm of knowledge, skills and attitudes as a whole, students become more active, creative, and challenged to create new innovations by utilizing the items from the environment where they live
\end{abstract}

\section{PENDAHULUAN}

Maju mundurnya suatu bangsa, sangat ditentukan oleh generasi muda, dan bagaimana suatu bangsa mempersiapkan generasi mudanya di masa yang akan datang, sangat bergantung pada pola pendidikan yang dijalankan di negara tersebut. Jadi sangat tidak heran di negara maju seperti Jepang, anak-anak kecil sudah di perkenalkan dengan pembelajaran komputer dan robotik beberapa tahun yang lalu, hal ini dalam rangka untuk mempersiapkan generasi mudanya dalam menghadapai era industri 4.0 yang saat ini sedang berlangsung, dimana segala segi kehidupan masyarakat tidak bisa lepas dari

\footnotetext{
* Corresponding author.

E-mail address: faridawati308@gmail.com

https://doi.org/10.12928/spekta.v1i2.2826
} 
komputer, internet, dan mesin otomatis. Bagi bangsa Indonesia sendiri, harus segera bangkit untuk mengejar ketertinggalan, dengan segera mungkin memperbaiki kualitas pendidikan di Indonesia, salah satunya dengan memberikan pendidikan yang sifatnya lebih aplikatif. Metode pembelajaran konvensional satu arah, dimana guru sebagai center of point sudah tidak lagi relevan untuk diterapkan di era industri 4.0. Kecepatan teknologi informasi membuat siswa dapat mengases informasi yang diperlukan terkait dengan pembelajaran yang di perlukan tanpa harus menunggu di ajari oleh guru di kelas. Pendidik utamanya guru harus selalu belajar dan update teknologi sehingga tidak tersingkirkan oleh perkembangan jaman. Salah satu cara penerapan pendidikan yang bersifat aplikatif adalah menerapkan sistem pembelajaran Science, Technology, Engineering and Mathematics (STEM). Beberapa hasil penelitian menunjukkan bahwa pembelajaran sains dalam konteks teknologi dan rancang bangun sangat potensial meningkatkan literasi sains. Siswa dapat memaknai lebih dalam arti penting sains bagi perkembangan teknologi, dan sebaliknya metode STEM bisa menjadi alternatif pembelajaran sains yang dapat membangun generasi muda agar mampu menghadapi abad 21 yang penuh tantangan (Permanasari, 2016; Ismayani, 2016). Faktor-faktor yang harus diperhatikan agar guru dapat melaksanakan integrasi pembelajaran STEM secara efektif telah di jelaskan (Stohlmann, Moore dan Roehrig, 2012; Kennedy dan Odell, 2014).

Harus diakui kualitas pendidikan di Indonesia masih tidak merata, sekolahan di pulau Jawa mempunyai kualitas yang lebih baik bila di bandingkan dengan kualitas pendidikan di Indonesia bagian timur. Pun begitu kualitas pendidikan di pulau Jawa sendiri juga mengalami perbedaan antara sekolahan yang berada di daerah atau di perkotaan, sekolahan di perkotaan sering kali memiliki kualitas yang lebih baik bila dibandingkan dengan kualitas sekolahan yang berada di daerah atau pedesaan, di lihat dari segi kelengkapan sarana dan prasarana serta kualitas tenaga pengajar. Sehingga dalam rangka untuk meningkatkan kualitas pendidikan di daerah, maka disusunlah program pengabdian masyarakat dengan topik pembelajaran robotik bagi siswa sekolah dasar dengan menggunakan metode STEM. Pembelajaran robotik ini sengaja di berikan dengan sasaran sekolahan yang berada di daerah, di karenakan untuk sekolahan di perkotaan pembelajaran robotik sudah menjadi hal yang lumrah diberikan/ditawarkan sebagai unggulan program kegiatan sekolahan, dalam rangka menarik minat masyarakat untuk mendaftarkan anak-anaknya disekolahan tersebut. Sedangkan untuk sekolahan di daerah pembelajaran robotik masih menjadi sesuatu yang sulit untuk diterapkan, dengan alasan sumber daya manusia yang kurang mumpuni dan keterbatasan dana, untuk itulah maka pembelajaran robotik dengan menggunakan metode STEM ini di rancang berbasiskan bahan alam yang mudah di dapatkan di sekitar lingkungan sekolahan, dengan harga yang murah. Beberapa penelitian terkait pembelajaran robotik di sekolahan telah dilakukan oleh beberapa peneliti antara lain (Syarif, Syam dan Setiawan, 2019), (Arifin, 2017). Pembelajaran robotik sebagai salah satu kurikulum disekolahan juga di teliti oleh beberapa peneliti antara lain (Yilmaz dkk., 2012; Widiastuti, Arifin dan Widiawan, 2016; Zamisyak et al., 2016; Kabátová dan Pekárová, 2010).

Terdapat dua kegiatan dalam pengabdian masyarakat ini, yang pertama adalah kegiatan pelatihan pembelajaran robotik, yang diberikan kepada guru-guru pembina perwakilan dari sekolahan-sekolahan yang terdapat di desa Catak Gayam, kecamatan Mojowarno, kabupaten Jombang, Jawa Timur, terdiri dari empat sekolahan yaitu SDN Catak Gayam I, SDN Catak Gayam 2, MI Toriqul Huda, dan MI Darul Faizin. Kegiatan kedua adalah pembelajaran robotik kepada siswa-siswi yang diwakili oleh siswa-siswi dari SDN Catak gayam I, sebanyak 78 siswa. Pada pelatihan pembelajaran robotik ini, 
akan diajarkan bagaimana membuat robot sederhana, dengan memanfaatkan benda-benda yang mudah di dapatkan di lingkungan sekitar sekolahan. Pembelajaran robotik ini dijalankan dengan menggunakan sistim Action Learning (Welskop, 2013; Bahri Ys et al., 2011; Putra dan Harahap, 2018; Laurenty dan Rahmad, 2017) dimana pembina/guru akan mengajari siswa dengan cara menjelaskan dan mempraktekkan secara langsung, dan meminta siswa untuk melakukan hal yang sama.

Sebagai hasil akhir kegiatan adalah berupa buku modul pembelajaran robotik bagi siswa sekolah dasar, yang harapanya kedepan bisa digunakan oleh sekolahan dalam menyusun kurikulum pendidikan di sekolahan, sehingga muncul model variasi pembelajaran baru, yang membuat siswa semakin aktif dan kreatif, sehingga beberapa tahun kedepan akan tercipta generasi-generasi muda yang unggul dan berinovasi tinggi, yang mampu membawa kemajuan bagi bangsa Indonsesia

\section{METODE PELAKSANAAN}

1. Langkah-langkah yang dilakukan dalam pengabdian masyarakat ini adalah :

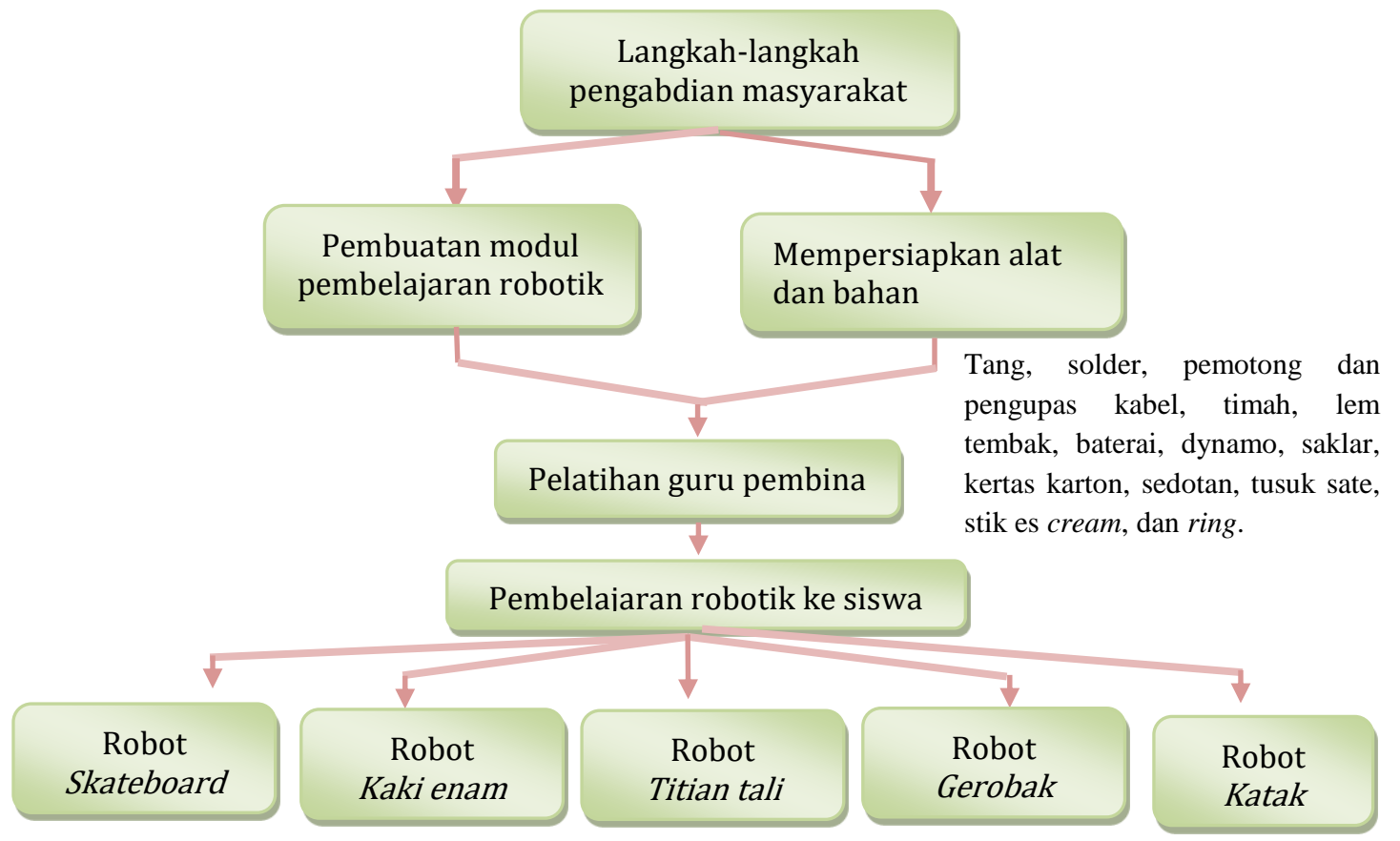

Dalam pengabdian masyarakat ini dipilih 5 jenis robot untuk di praktekkan pembuatannya yaitu robot katak, robot kaki enam, robot gerobak, robot skate board, dan robot titian tali, yang bahan-bahannya bisa dilihat pada gambar 1a, 1b, 1c, 1d dan 1e, sedangkan diagram rangkaian robot bisa dilihat pada gambar 1.f
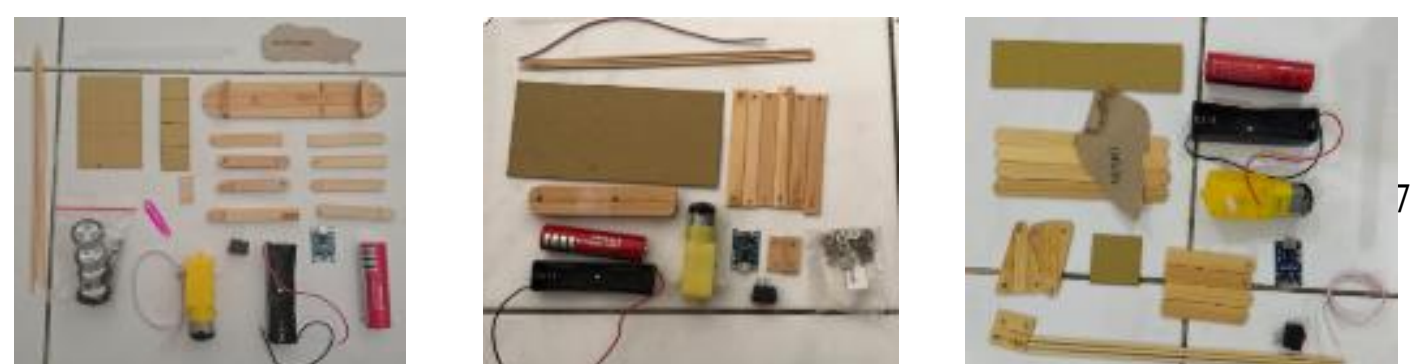
2. Subjek penelitian dan evaluasi kegiatan

Subyek penelitian untuk kegiatan pengabdian masyarakat ini adalah siswa-siswi kelas 5 dan 6 SDN Catak Gayam I, kecamatan Mojowarno Kabupaten Jombang, Jawa Timur. Terdiri dari 40 siswa kelas 5 dan 38 siswa kelas 6 . Metode yang digunakan dalam mengevaluasi kegiatan pembelajaran robotik ini adalah:

1. Metode Observasi, yaitu metode observasi selama kegiatan berlangsung, untuk mengetahui proses keterlaksanaan pembelajaran

2. Metode Tes Oral, yaitu metode untuk menilai sejauh mana pehaman siswa terhadap materi pembelajaran yang telah diberikan, tes berupa pertanyaan dasar terkait alat dan bahan yang digunakan, dan proses pembuatan robot.

3. Metode Angket, yaitu metode pemberian angket, untuk mengetahui respon siswa terhadap kegiatan pembelajaran robotik dengan metode Action Learning STEM.

\section{HASIL DAN PEMBAHASAN}

Pelatihan pembelajaran robot ini dilakukan dengan menggunakan sistim action learning STEM, yaitu metode pembelajaran praktek secara langsung, dengan mengintegrasikan materi sains, technology, engineering, and mathematics. Pembelajaran robotik ini juga mempunyai peran yang cukup signifikan terhadap perubahan metode pembelajaran di sekolah dan sesuai dengan program mentri pendidikan tentang merdeka belajar, karena siswa tidak hanya belajar teori di kelas, tetapi juga langsung mempraktekkannya melalui media robot. Selain itu keseluruhan pembelajaran robotik juga mendukung siswa untuk mendapatkan materi yang saling terintegrasi antara subyek pelajaran science, technology, engineering, dan mathematics. Melalui metode 
pembelajaran integrasi STEM siswa diharapkan bisa mendapatkan materi yang sesuai dengan perkembangan zaman, selain itu metode STEM pada pembelajaran juga berperan penting dalam pemenuhan ketrampilan abad-21 yang dikenal dengan istilah 4C, yaitu Creativity (kreatifitas), Critical thinking (berpikir kritis), Communication (Komunikasi), dan Colaboration (kolaborasi). Untuk mengetahui tolak ukur keberhasilan pengabdian masyarakat ini, maka dilakukan beberapa evaluasi kegiatan, yaitu dengan menggunakan metode observasi, metode tes oral, dan metode angket. Hasil evaluasi kegiatan dengan menggunakan metode observasi, menunjukkan bahwa semua peserta berhasil menyelesaikan pembuatan robot sesuai dengan modul yang di berikan. Sebagaian besar peserta baik dari guru pembina dan juga murid, terlihat sangat enjoy dan menikmati acara, dan sebagian besar dari guru pembina sepakat bahwa pembelajaran robotik, bisa diterapkan pada pembelajaran matematika untuk bab luas bidang dan bangun datar. Selain itu pembelajaran robotik juga bisa diterapkan pada pelajaran tematik sains untuk bab gaya gerak dan energi, membuat pesawat sederhana, dan bekerja sama untuk mencapai tujuan. Setelah menyelesaikan proyek perakitan robot sesuai dengan modul yang telah di tentukan, dilakukan tes oral kepada masing-masing kelompok siswa untuk mengetahui sejauh mana pemahaman siswa terhadap materi pembelajaran yang sudah diberikan, tes berupa beberapa pertanyaan terkait alat dan bahan dan meminta siswa untuk menjelaskan secara lisan apa yang telah mereka lakukan selama proses pembelajaran. Foto kegiatan pengabdian pembelajaran robotik bisa dilihat pada gambar 1 dan gambar 2. Sedangkan foto beberapa hasil robotik karya siswa bisa dilihat pada gambar 3 .

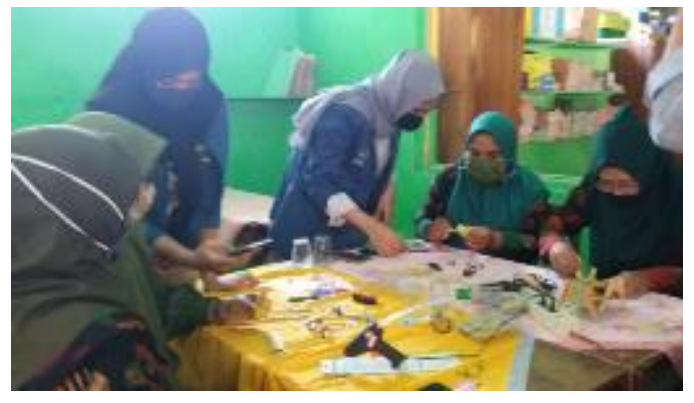

Gambar 2 Pelatihan Pembelajaran Robotik Untuk Guru Pembina
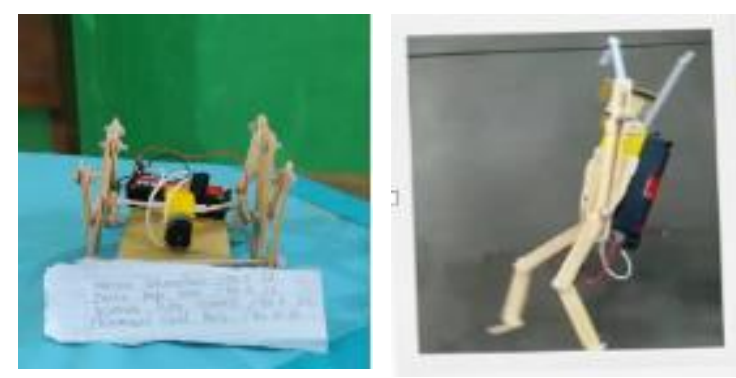

Gambar 4 Hasil Robotik Karya

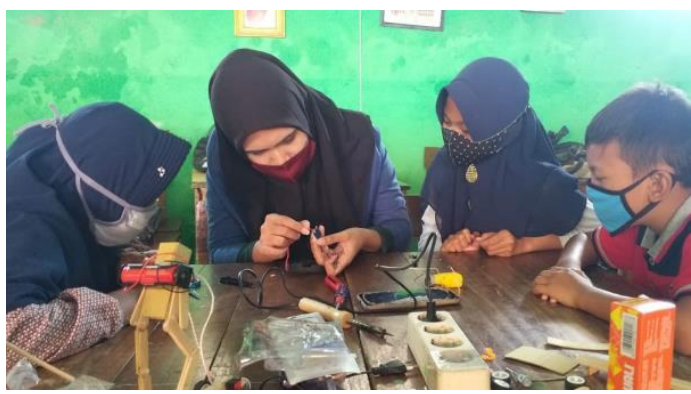

Gambar 3 Pelatihan Pembelajaran Robotik Untuk Siswa
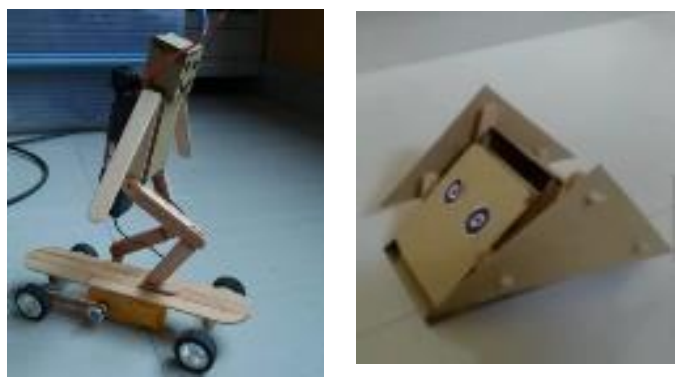

Dari hasil tes oral menunjukkan bahwasanya dari total 78 siswa, sebanyak 66 siswa atau sekitar $85 \%$ telah paham materi pembelajaran yang diberikan, dan sebanyak 10 siswa 
atau sekitar $13 \%$ masuk kategori agak paham terhadap materi yang diberikan,Sedangkan sebanyak 2 siswa atau sekitar 2\%, masuk kateori tidak paham terhadap materi karena tidak bisa menyebutkan alat-alat yang digunakan dan langkah-langkah proses perakitan robot. Persentase pemahaman siswa terhadap materi pembelajaran robotik bisa dilihat pada gambar 5 .

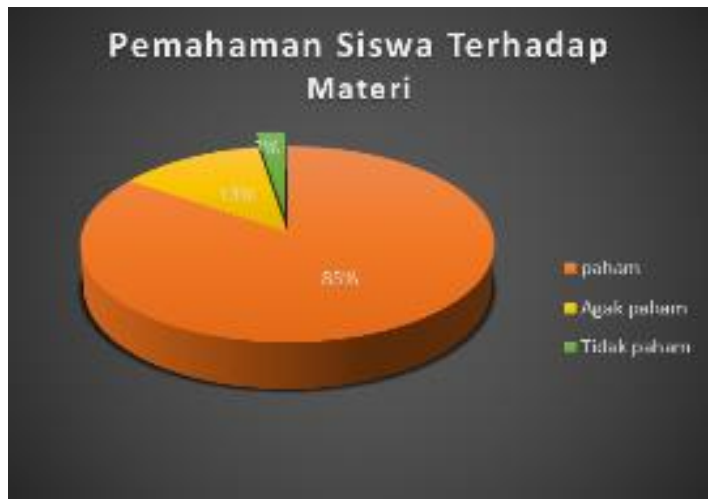

Gambar 5 Persentase Pemahaman Siswa Terhadap Materi

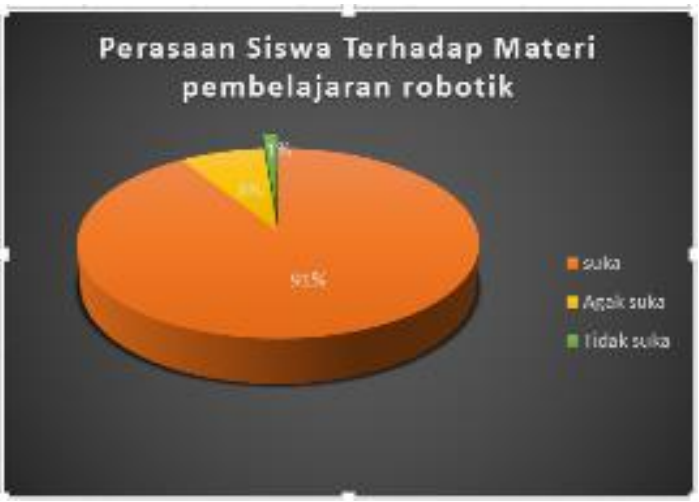

Gambar 6 Persentase Perasaan Siswa Terhadap Materi

Hasil evaluasi dengan menggunakan metode angket, menunjukkan hasil sebanyak 91 persen menyatakan suka dengan pembelajaran robotik, sebanyak 8 persen menyatakan agak suka, dan sebanyak 1 persen menyatakan tidak suka, yang dapat di lihat pada gambar 6. Dari metode angket ini selanjutnya diketahui beberapa alasan kenapa siswa menyukai pembelajaran robotik dan juga diketahui alasan kenapa siswa tidak menyukai pembelajaran robotik. Sebanyak 61 persen siswa menyukai pembelajaran robotik dengan alasan karena menyenangkan, 29 persen siswa mengatakan pembelajaran robotik menarik, sebanyak 7 persen siswa menyatakan menyukai pembelajaran robotik karena mudah, dan 3 persen meyukai pembelajaran robotik dikarenakan hasil jadi robot terlihat lucu, Grafik alasan siswa menyukai pembelajaran robotik ini bisa kita lihat pada gambar 7, sedangkan untuk siswa yang menyatakan agak suka dan tidak suka dengan pembelajaran robotik, di dapatkan beberapa alasan yang bisa kita ketahui dari gambar 8 , sebanyak 42 persen memberikan alasan tidak menyukai pembelajaran robotik dikarenakan susah, 33 persen memberikan alasan karena waktu yang dibutuhkan untuk membuat robot lama, dan sebanyak 8 persen siswa menyatakan tidak menyukai pembelajaran robotik dikarenakan memang tidak menyukai robot.

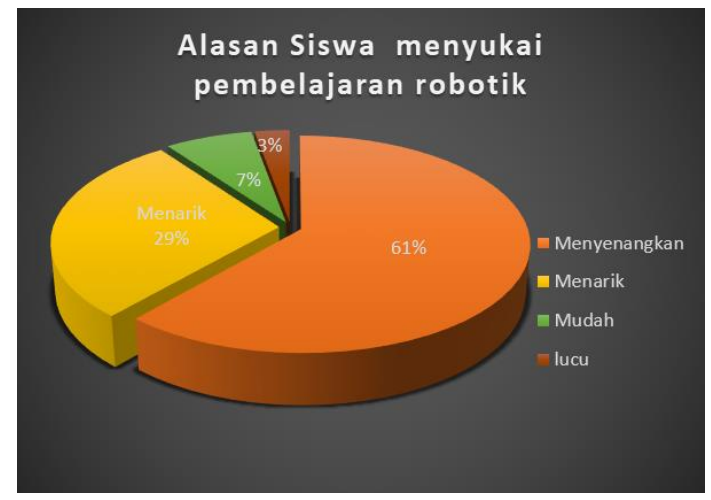

Gambar 7 Persentase Alasan Siswa Menyukai Pembelajaran Robotik

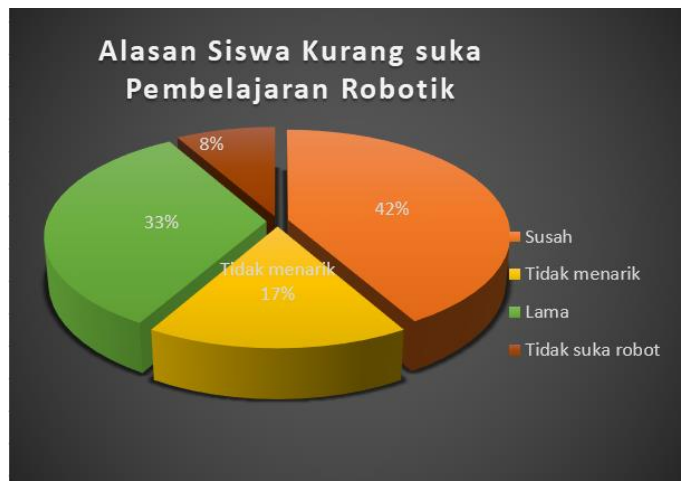

Gambar 8 Persentase Alasan Siswa Kurang Menyukai Pembelajaran 90 


\section{KESIMPULAN}

Pembelajaran robotik bagi siswa sekolah dasar ini, sangat sesuai untuk diterapkan di sekolahan, baik sebagai kurikulum resmi, atau sebagai kurikulum muatan lokal sekolahan, karena pembelajaran robotik ini mampu mengembangkan kompentensi siswa dalam ranah pengetahuan, ketrampilan, dan sikap secara utuh. Selain itu pembelajaran robotik dengan menggunakan sistim action learning STEM ini, membuat siswa menjadi semakin aktif, kreatif, dan tertantang untuk menciptakan inovasi-inovasi baru dengan memanfaatkan barang-barang yang terdapat di sekitar lingkungan tempat tinggal.

\section{UCAPAN TERIMA KASIH}

Terima kasih kepada Direktorat Riset dan Pengabdian Kepada Masyarakat Institut Teknologi Sepuluh Nopember (ITS) yang telah memberikan dukungan dan hibah dana pengabdian masyarakat berbasis produk tahun 2020, sehingga kegiatan pengabdian masyarakat ini bisa berjalan dengan lancar.

\section{DAFTAR PUSTAKA}

Anna Permanasari, (2016) 'STEM Education: Inovasi dalam Pembelajaran Sains Prosiding', Seminar Nasional Pendidikan Sains (SNPS).

Arifin, M. A. S. (2017) 'Rancang Bangun Prototype Robot Lengan Menggunakan Flex Sensor Dan Accelerometer Sensor Pada Lab Mikrokontroler Stmik Musirawas', ILKOM Jurnal Ilmiah, 9(3), pp. 255-261. doi: 10.33096/ilkom.v9i3.152.255-261.

Bahri Ys, S. et al. (2011) 'Action Research on the Implementation of Active Learning at an Elementary School in Aceh', Excellence in Higher Education, 2(2), pp. 70-78. doi: 10.5195/EHE.2011.55.

Ismayani, A. (2016) 'Pengaruh Penerapan Stem Project- Based Learning Terhadap Kreativitas Matematis Siswa Smk', 3, p. 9.

Kabátová, M. and Pekárová, J. (2010) 'Learning how to teach robotics', p. 9.

Kennedy, T. J. and Odell, M. R. L. (2014) 'Engaging Students In STEM Education', p. 13.

Laurenty, F. and Rahmad, M. (no date) 'Application Of Learning By Science Integration And Religion Approach To Increase Students Motivation Physics Learning', p. 9.

Putra, T. and Harahap, B. (2018) 'Penerapan Strategi Belajar Action Learning Dan Strategi Belajar Mind Map Dalam Ektrakurikuler Pelajaran Agama Di Sd Negeri 064979 Setia Budi Medan', p. 15.

Stohlmann, M., Moore, T. and Roehrig, G. (2012) 'Considerations for Teaching Integrated STEM Education', Journal of Pre-College Engineering Education Research, 2(1), pp. 28-34. doi: 10.5703/1288284314653.

Syarif, S., Syam, R. and Setiawan, A. (2019) 'Robot Penggerak Dua Roda Sebagai Media Pembelajaran Robotik bagi Siswa SMA 05 Barru', 2, p. 9.

Welskop, W. (2013) 'Action learning in education'. doi: 10.13140/RG.2.1.4513.8006.

Widiastuti, I., Arifin, S. and Widiawan, B. (2016) 'Peningkatan Kreativitas Siswa SD Negeri Karangrejo 2 Melalui Ekstrakurikuler Robotika', p. 4.

Yilmaz, M. et al. (2012) 'A Two-semester Project-based Robotics Curriculum', in 2012 ASEE Annual Conference \& Exposition Proceedings. 2012 ASEE Annual Conference \& Exposition, San Antonio, Texas: ASEE Conferences, p. 25.117.1-25.117.17. doi: 10.18260/1-2--20877.

Zamisyak, O. et al. (2016) 'Educational Multifunction Robot (Indobot) Sebagai Robot Edukasi', p. 12. 
SPEKTA

Jurnal Pengabdian Kepada Masyarakat : Teknologi dan Aplikasi

Vol. 1, No. 2, Desember 2020

Halaman ini sengaja dikosongkan 